\title{
Tandem peroral endoscopic myotomy (POEM) and transoral incisionless fundoplication: a strategy to reduce reflux after POEM
}

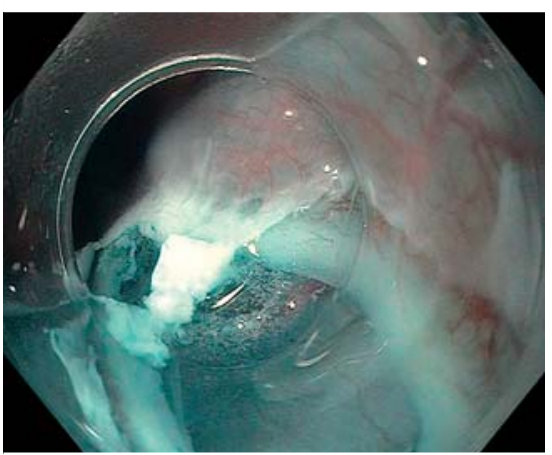

- Fig. 1 Mucosotomy.

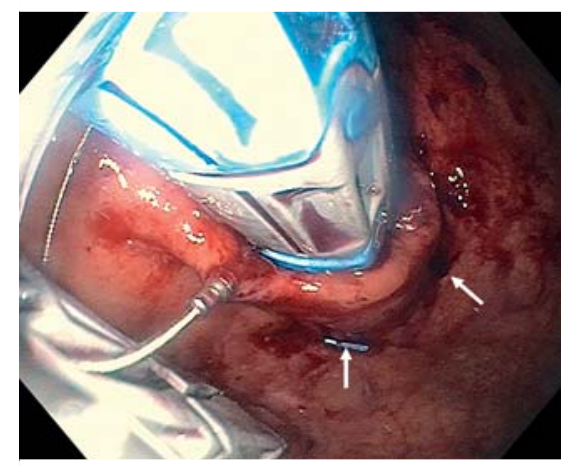

-Fig. 4 Transoral incisionless fundoplication device with $\mathrm{H}$ fasteners (arrows).

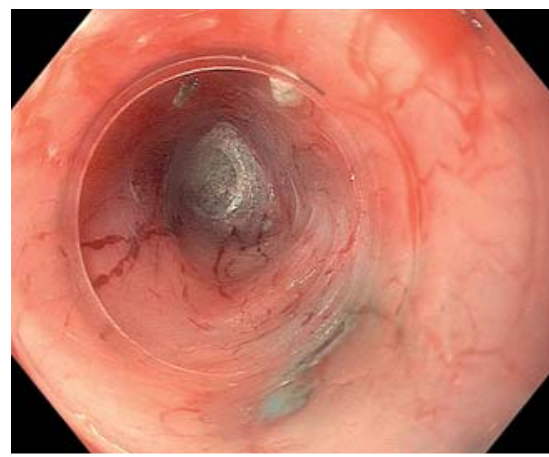

- Fig. 2 Submucosal tunnel.

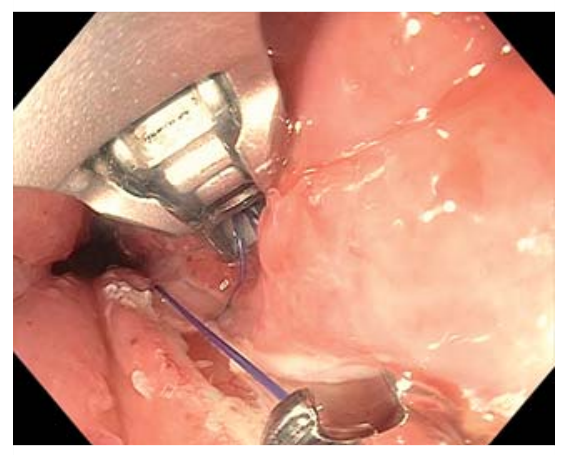

- Fig. 5 Mucosotomy closure with endoscopic suturing device.
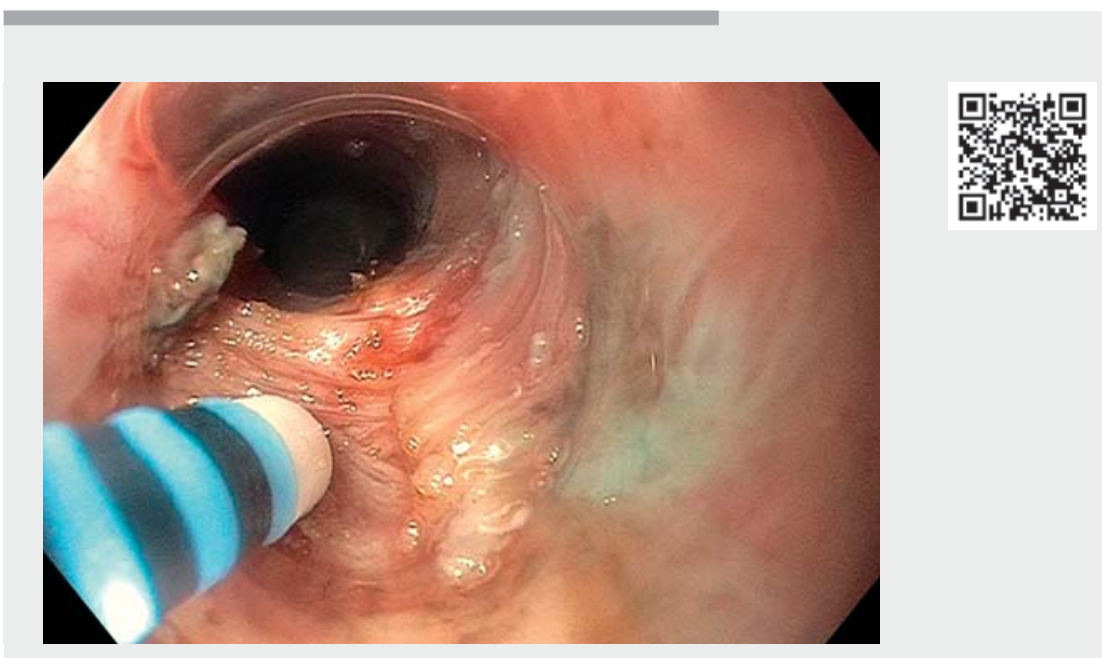

$\checkmark$ Video 1 Tandem peroral endoscopic myotomy and transoral incisionless fundoplication. Mucosotomy closure with endoscopic suturing.

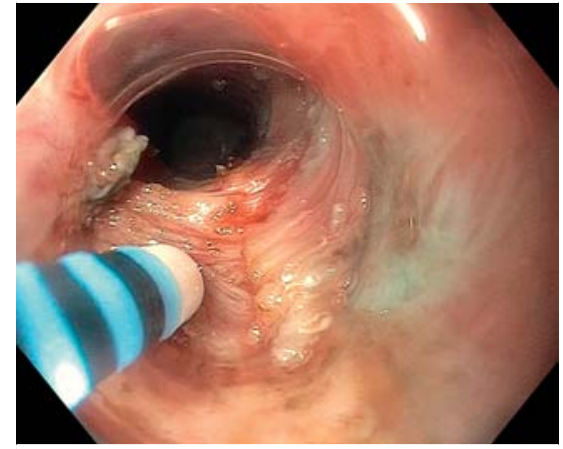

- Fig. 3 Myotomy performed with a multipurpose electrosurgical knife.

Peroral endoscopic myotomy (POEM) is an effective treatment for achalasia, comparable to laparoscopic Heller myotomy (LHM) [1]. Gastroesophageal reflux disease (GERD) is a common adverse event, and POEM vs. LHM has higher abnormal acid exposure ( $39 \%$ vs. $16.8 \%$ ) and esophagitis (29.4\% vs. $7.6 \%$ ) [2,3]. Transoral incisionless fundoplication (TIF) is an endoscopic intervention for GERD that reduces acid exposure [4,5]. A 41-year-old man with manometry-confirmed type II achalasia presented with dysphagia to solids and liquids and weight loss. His Eckardt score was 11 out of 12 (severe symptoms). The plan was to perform POEM followed by TIF in a single session to reduce post-POEM reflux ( $\triangleright$ Video 1 ).

The endoscope was fitted with a clear, tapered cap. A submucosal injection of saline plus methylene blue followed by mucosotomy were performed $10 \mathrm{~cm}$ proximally to the gastroesophageal junction (GEJ) ( Fig. 1). The submucosal space was entered and the tunnel extended $2 \mathrm{~cm}$ beyond the GEJ ( $>$ Fig. 2). A full-thickness myotomy was extended $2 \mathrm{~cm}$ beyond the lower esophageal sphincter ( $\mathbf{F i g . 3}$ ). The fundoplication device was inserted and the GEJ was viewed in retroflexion. Tissue was pulled into the device using a tissue helix and 
suction. Device manipulation and deployment of $28 \mathrm{H}$-shaped full-thickness fasteners were used to augment the GEJ flap valve to create a 270-degree wrap $2 \mathrm{~cm}$ in length (> Fig.4). The mucosotomy was closed by endoscopic suturing ( Fig.5).

The patient was discharged the day after tandem POEM-TIF. He regained weight and his Eckhardt score improved from 11 to 3 . He reported no reflux or need for proton pump inhibitors. Follow-up esophagogastroduodenoscopy 9 months later showed no esophagitis.

Tandem POEM-TIF is a strategy for prevention of reflux after POEM, especially in young patients. Further study is needed to determine long-term safety and efficacy.

Endoscopy_UCTN_Code_CPL_1AH_2AH

\section{Competing interests}

Nikhil A. Kumta is a consultant for Apollo Endosurgery, Boston Scientific, Intuitive Surgical, and Olympus.
The authors

Nicholas A. Hoerter ${ }^{\circledR}$ Rebekah E. Dixon, Christopher J. DiMaio $\oplus^{\circ}$ Satish Nagula, David Greenwald, Nikhil A. Kumta

Center for Advanced Colonoscopy and Therapeutic Endoscopy at Sinai (CACTES), Dr. Henry D. Janowitz Division of Gastroenterology, Icahn School of Medicine at Mount Sinai, New York, New York, United States

\section{Corresponding author}

Nikhil A. Kumta, MD, MS

Mount Sinai Hospital, One Gustave L. Levy Place, Box 1069, New York, NY, 10029, United States

Nikhil.Kumta@mountsinai.org

\section{References}

[1] Schlottmann F, Luckett DJ, Fine J et al. Laparoscopic Heller myotomy versus peroral endoscopic myotomy (POEM) for achalasia: a systematic review and meta-analysis. Ann Surg 2018; 267: 451-460

[2] Stavropoulos SN, Desilets DJ, Fuchs K-H et al. Per-oral endoscopic myotomy white paper summary. Gastrointest Endosc 2014; 80 : $1-15$

[3] Repici A, Fuccio L, Maselli R et al. GERD after per-oral endoscopic myotomy as compared with Heller's myotomy with fundoplication: a systematic review with meta-analysis. Gastrointest Endosc 2018; 87: 934-943
[4] Trad KS, Barnes WE, Prevou ER et al. The TEMPO trial at 5 years: transoral fundoplication (TIF 2.0) is safe, durable, and cost-effective. Surg Innov 2018; 25: 149-157

[5] Bell RCW, Barnes WE, Carter BJ et al. Transoral incisionless fundoplication: 2-year results from the prospective multicenter U.S. study. Am Surg 2014; 80: 1093-1105

Bibliography

Endoscopy 2022; 54: E368-E369

DOI 10.1055/a-1540-6558

ISSN 0013-726X

published online 9.8.2021

(c) 2021. Thieme. All rights reserved. Georg Thieme Verlag KG, Rüdigerstraße 14,

70469 Stuttgart, Germany

ENDOSCOPY E-VIDEOS

https://eref.thieme.de/e-videos

口回 Endoscopy E-Videos is an open access online section, 回侜: reporting on interesting cases and new techniques in gastroenterological endoscopy. All papers include a high quality video and all contributions are freely accessible online. Processing charges apply (currently EUR 375), discounts and wavers acc. to HINARI are available.

This section has its own submission website at https://mc.manuscriptcentral.com/e-videos 